\title{
A secretomic study on human hepatocellular carcinoma multiple drug-resistant cell lines
}

\author{
YI XIANG ${ }^{1}$, YI LIU ${ }^{1}$, YIXUAN YANG ${ }^{1}$, HUAIDONG HU ${ }^{2}$, PENG HU $^{1,2}$, \\ HONG REN $^{1,2}$ and DAZHI ZHANG ${ }^{1}$ \\ ${ }^{1}$ Department of Infectious Diseases, The Second Affiliated Hospital, Chongqing Medical University; \\ ${ }^{2}$ Institute for Viral Hepatitis, Key Laboratory of Molecular Biology for Infectious Diseases, Ministry of \\ Education, The Second Affiliated Hospital of Chongqing Medical University, Chongqing, P.R. China
}

Received February 8, 2015; Accepted May 25, 2015

DOI: $10.3892 /$ or.2015.4106

\begin{abstract}
The aim of this study was to identify pivotal dysregulated proteins that are biomarkers for multiple drug resistance (MDR) of human hepatocellular carcinoma (HCC). The secretome profiles of the human HCC MDR cell line BEL7402/5-FU and its parental cell line BEL7402 were comparatively analyzed using isobaric tags for the relative and absolute quantification (iTRAQ)-coupled 2D LC-MS/MS. In total, 279 differentially expressed proteins were identified, of which, with a consistent result in the duplex test, 131 proteins were overexpressed in BEL7402/5-FU compared to its parental cell line, and 56 proteins were underexpressed. Several differentially expressed proteins determined by western blot analysis were also validated. The association of MDR with one of the highly regulated proteins, $\alpha-2$-HS-glycoprotein (AHSG) was determined. This study detailed the application of iTRAQ technology to MDR biomarkers in the HCC cell secretome. The results showed that differentially expressed proteins that may be associated with MDR of HCC provide valuable additional information with regard to understanding the role of MDR.
\end{abstract}

\section{Introduction}

Liver cancer remains one of the most common types of cancer worldwide and is ranked in the top 10 causes of cancer-associated mortalities (1). Hepatocellular carcinoma (HCC), the most common type of liver cancer pathology, has been a major

Correspondence to: Professor Dazhi Zhang, Department of Infectious Diseases, The Second Affiliated Hospital, Chongqing Medical University, 76 Lin Jiang Road, Yu Zhong, Chongqing, 400010, P.R. China

E-mail: xy_198901@163.com

Abbreviations: HCC, hepatocellular carcinoma; MDR, multiple drug resistance; iTRAQ, isobaric tags for relative and absolute quantification; TMA, tissue microarray

Key words: hepatocellular carcinoma, multiple drug resistance, secretome, iTRAQ threat to human life, especially in regions where viral hepatitis is prevalent, such as in Asia (hepatitis B) and America (hepatitis C). Multiple treatments, including chemoembolization, radiofrequency ablation (RFA), adjuvant therapy, surgical resection and liver transplantation, are available options for $\mathrm{HCC}$ at different stages. However, HCC is prone to be in an advanced stage when diagnosed, rendering it unresectable and responds poorly to chemotherapeutic drugs, due to multiple drug resistance (MDR). MDR refers to the phenomenon whereby microorganisms or tumor cells simultaneously resist several varieties of drugs which themselves are structurally and functionally different (2-4). MDR in cancer emerges in ongoing treatment with an anticancer drug when the cancer cells become resistant to both the chemical in use as well as to other chemotherapeutic drugs. It is generally accepted that early identification of MDR is useful in selecting the optimal treatment protocol and predicting the prognosis of the cancer. Therefore, identifying biomarkers associated with drug resistance is a highly desirable research purpose.

Secretomics is a branch of proteomics that focuses on the proteins secreted by cells, tissues or organisms. Increasing attention has been given to the study of Secretomics, because secreted proteins are believed to be essential to numerous physiological and pathological processes such as glucose and lipid metabolism, cell signal transduction, matrix remodeling, drug delivery and invasion of malignant cells. It is deemed likely that some proteins connected to the chemotherapeutic drug resistance of $\mathrm{HCC}$ are to be found from the secretome of HCC multi-drug-resistant cell line BEL7402/5-FU. Although several proteins such as BCRP, MRP, P-gp and ANXA3 have been found to correlate with the MDR phenomenon, secretory proteins in the MDR phenotype are worthy of study.

The lack of abundance is the main obstacle to conventional proteomic approaches. Secretory proteins are difficult to detect and analyze by two-dimensional gel electrophoresis (2-DE) owing to the low protein concentration in cell media or body fluids, as well as to the existence of hydrophobic proteins (7). Consequently, the conventional 2-DE-conducted proteomic assay is not suited to secretomic studies. Isobaric tags for the relative and absolute quantification (iTRAQ) analysis is an emerging quantitative proteomics technology that labels peptides with isotope-coded covalent tags to study changes 
of protein expression in different samples. With respect to conventional approaches, iTRAQ has an advantage in accuracy and can analyze eight different samples simultaneously. In the present study, the iTRAQ-based proteomic approach was applied to identify differentially expressed secretory proteins between BEL7402 and BEL7402/5-FU.

\section{Materials and methods}

Cell lines. Cell lines used in this study were obtained from the Cancer Cell Bank of the Chinese Medical Science Institute. BEL7402/5-FU is an MDR HCC cell line that was induced by 5 -fluorouracil $(5-\mathrm{Fu})$ from the human $\mathrm{HCC}$ cell line BEL7402. RPMI-1640 medium and fetal bovine serum (FBS) were purchased from Gibco (Grand Island, NY, USA). The complete medium for BEL7402 and BEL7402/5-FU consisted of $89 \%$ RPMI-1640 medium, 10\% FBS and 1\% penicillin-streptomycin solution. By adding $20 \mathrm{mg} / \mathrm{l} 5$-Fu to the complete medium, the BEL7402/5-FU cell line maintained its biological characteristics of MDR. Cell lines were cultured in a water incubator (Thermo Fisher Scientific, Rockford, IL, USA) at $37^{\circ} \mathrm{C}$ and $5 \% \mathrm{CO}_{2}$.

Half maximal inhibitory concentration (IC50) determination. The cytotoxicity of chemotherapeutic drugs to BEL7402 and its MDR cell line were measured by a WST- 8 assay (5). BEL7402 and BEL7402/5-FU cells were counted and placed in 96-wells at a density of $5 \times 10^{3}$ cells/well, and then cultured in an incubator at $37^{\circ} \mathrm{C}$ for $24 \mathrm{~h}$ before being treated with chemotherapeutic drugs. 5-Fu, cisplatin, adriamycin and vincristine (VCR) in graded concentrations were added to the two types of cells. After treatment for $48 \mathrm{~h}$, the medium was replaced with fresh medium containing 10\% WST- 8 reagent, and the cells were incubated for an additional 1-4 h until their optical density was measured at $450 \mathrm{~nm}$. The IC50 of BEL7402 and BEL7402/5-FU for each drug was analyzed using IBM SPSS Statistics 21 software (SPSS Inc., Chicago, IL, USA) by means of probit analysis (6).

Secretory protein extraction. The secretory proteins of BEL7402 and BEL7402/5-FU were extracted through ultrafiltration. When BEL7402 and BEL7402/5-FU were 90\% confluent, the culture media were replaced with basic RPMI-1640 medium after the residual serum was washed away with PBS. Twentyfour hours after instituting this serum-free culture, the media of each cell line were collected and concentrated by centrifugation at $4^{\circ} \mathrm{C}$ for $1 \mathrm{~h}$ using centrifugal filter devices from Amicon (Carrigtwohill, Co., Cork, Ireland). The resulting concentrated solution was removed and placed into a tube and precipitated overnight with acetone at $20^{\circ} \mathrm{C}$. Subsequently, the precipitated samples were separated by high-speed centrifugation, and then dissolved in a buffer containing $0.5 \mathrm{M}$ triethylammonium bicarbonate and $8 \mathrm{M}$ urea (urea TB buffer). Protein samples were stored at $-80^{\circ} \mathrm{C}$ prior to isotope labeling.

iTRAQ labeling. Secretory protein samples were quantified using a 2-D Quant kit purchased from Amersham Biosciences, and diluted with the urea TB buffer to obtain a final concentration of $5 \mathrm{mg} / \mathrm{ml}$. A $100 \mu \mathrm{g}$ protein/sample of BEL7402 and BEL7402/5-FU was employed for isotope labeling, and a duplex was set for the HCC cell and its MDR phenotype, respectively. Samples in each tube were denatured and cysteine-blocked using buffers in the iTRAQ Buffer kit (AB Sciex, Foster City, CA, USA). Having been digested with $5 \mu \mathrm{g}$ trypsin (Promega, Madison, WI, USA) at $37^{\circ} \mathrm{C}$ overnight and desiccated using a vacuum pump, the peptides were dissolved in isopropanol and then subjected to iTRAQ labeling. Isotope tags were allocated as follows: i) BEL7402 secretory protein -113 and -115 tags; and ii) BEL7402/5-FU secretory protein -114 and -116 tags. The labeled samples were mixed together for further mass spectrometric (MS) analysis.

Peptide fractionation. Peptides labeled with isotope tags were fractionated as previously described (7). Briefly, the fractionation process is conducted through isoelectric focusing (IEF). Labeled samples were dissolved in Pharmalyte and urea solution, subjected to $\mathrm{pH}$ 3-10 IPG strips, and then focused on the IPGphor. The IPGphor IEF system was purchased from Amersham Biosciences (Uppsala, Sweden). Peptides were extracted from the gel using buffer A (2\% acetonitrile and $0.1 \%$ formic acid) and lyophilized in a vacuum pump. The fractions were desalinated using a solid phase extraction (SPE) column (Supelco, Bellefonte, PA, USA) and lyophilized again. The fractions were then stored at $-20^{\circ} \mathrm{C}$ prior to the MS analysis.

Mass spectrometric analysis. MS analysis was performed with the QStar ${ }^{\circledR}$ Elite hybrid mass spectrometer (Applied Biosystems, Foster City, CA, USA) coupled to a liquid chromatography system (Amersham, The Netherlands). Lyophilized samples were re-suspended in buffer $\mathrm{A}$, and $10 \mu \mathrm{l}$ was loaded on a capillary column for peptide separation. Peptides were separated by eluting with buffer A and a series of buffer B (98\% acetonitrile containing $0.1 \%$ formic) gradients at a $0.3 \mu \mathrm{l} / \mathrm{min}$ flow rate. The LC eluent was applied to the electrospray ionization (ESI) quadruple time-of-flight mass spectrometer (QTOF-MS) analysis. The mass spectrometer was operated in positive ion mode, with the mass range set at $300-2,000 \mathrm{~m} / \mathrm{z}$. The two most intensely ionized peptides $>20$ counts were selected for tandem mass spectrometry at a dynamic exclusion for $30 \mathrm{sec}$ with a tolerance of $\pm 50 \mathrm{mDa}$.

MS analysis data were processed using the ProteinPilot version 2.0 software (Applied Biosystems) and searched against the International Protein Index (IPI) human protein database (v3.77). Cysteine modified by methane thiosulfate (MMTS) was specified as a fixed modification. Relative quantification of proteins was determined using ratios of the peak areas at 113 , 114,115 and $116 \mathrm{Da}$, respectively. These values corresponded to the abundance of the tags applied to label the samples.

Western blot analysis. To verify the differentially expressed secretory proteins identified through MS analysis, western blotting was subsequently carried out. Figures for the total proteins of BEL7402 and its MDR cell line were calculated by lysing cells with a lysis buffer as previously described (9). Concentrations of each protein sample were determined using the 2D-Quant kit. Equal amounts of intercellular and secreted proteins were separated by SDS-PAGE electrophoresis and then transferred onto polyvinylidene fluoride (PVDF) membranes. The membranes were subsequently blocked with blocking buffer [5\% milk, $3 \%$ BSA or $0.04 \%$ gelatin in tris-buffered 
saline and Tween-20 (TBS-T)] at room temperature for $1 \mathrm{~h}$. The blocked membranes were incubated with specific primary antibodies (1:1,000-1:10,000 dilution in blocking buffer) overnight at $4^{\circ} \mathrm{C}$. Primary antibodies, including polyclonal and monoclonal against $\alpha-2-H S$-glycoprotein (AHSG), angiopoietin 1 (ANGPT1), vitronectin (VTN), SerpinF1, NAD(P)H dehydrogenase (quinone) 1 (NQO1) and lipocalin-2 (LCN2), were purchased from Abcam (Cambridge, MA, USA). Species-specific horseradish peroxidase-conjugated secondary antibodies were applied to incubate the membranes, which were previously washed three times in TBS-T. Reactions between the target proteins and specific antibodies were then visualized by enhanced chemiluminescence (ECL) reagent (GE Healthcare, Buckinghamshire, UK) through the ChemiDOC ${ }^{\mathrm{TM}} \mathrm{MP}$ imaging system (Bio-Rad, Hercules, CA, USA).

AHSG siRNA treatment to BEL7402/5-FU cell line. Three AHSG siRNA sequences (5'-ACACCUUCAUGGGUGUGG UCUCAUU-3', 5'-ACGCUCAGAACGGCUCCAAUUU-3' and 5'-UCGUCCUGCUCCUUUGUCUUGCUCA-3') and negative control siRNA purchased from Invitrogen-Life Technologies (Carlsbad, CA, USA) were each transfected into BEL7402/5-FU cells following the manufacturer's instructions. BEL7402/5-FU cells were evenly planted into 6-well plates and cultured until they were $60-80 \%$ confluent. AHSG siRNAs and negative control siRNA were incubated with the Lipofectamine ${ }^{\circledR} 2000$ Transfection reagent (Invitrogen-Life Technologies) for $20 \mathrm{~min}$ in Opti-MEM ${ }^{\circledR}$ I Reduced-Serum Medium (Gibco) prior to being transfected into BEL7402/5-FU cells. The final concentration of the siRNAs was $40 \mathrm{nmol} / 1$, which corresponded to the optimal concentration as measured in a pre-test. The medium in each well was replaced with RPMI-1640 complete medium 4-6 h after siRNA transfection and the cells were allowed to continue in culture for a further $48 \mathrm{~h}$. The apoptotic rate was detected by Annexin V-FITC/PI using flow cytometry (FCM). The viabilities of RNA-interfered cells were examined using WST- 8 following treatment with 5-Fu, adriamycin, VCR and cisplatin, respectively, in their IC50 concentrations for $48 \mathrm{~h}$. Simultaneously, AHSG protein expression of knockdown cells was determined by western blotting.

Immunohistochemistry. Immunohistochemistry (IHC) was performed on the tissue microarray (TMA) LV801a obtained from US Biomax, Inc. (Rockville, MD, USA). The TMA contained 40 cases of $\mathrm{HCC}$ and an equal amount of adjacent normal tissue. The IHC was performed as previously described (7). Paraffin-embedded HCC tissue sections were deparaffinized and rehydrated, and antigen retrieval was performed with $0.01 \mathrm{M}$ citrate for $5 \mathrm{~min}$. Endogenous peroxidase activity was quenched in $3 \% \mathrm{H}_{2} \mathrm{O}_{2}$ for $10 \mathrm{~min}$. Tissue sections were then blocked with $\mathrm{BSA}$, and incubated with specific monoclonal antibodies for AHSG (1:20), ANGPT1 (1:20), VTN (1:100), NQO1 (1:100), LCN2 (1:200) and SerpinF1 (1:400). The reactions were visualized by incubating with diaminobenzidine solution (DAB), counterstained with hematoxylin and evaluated under a light microscope. The protein expression levels were semi-quantitatively analyzed based on the percentage of positive cells, ranging from 0 to $100 \%$, and the staining intensity was counted as $0,1,2$, or 3 .

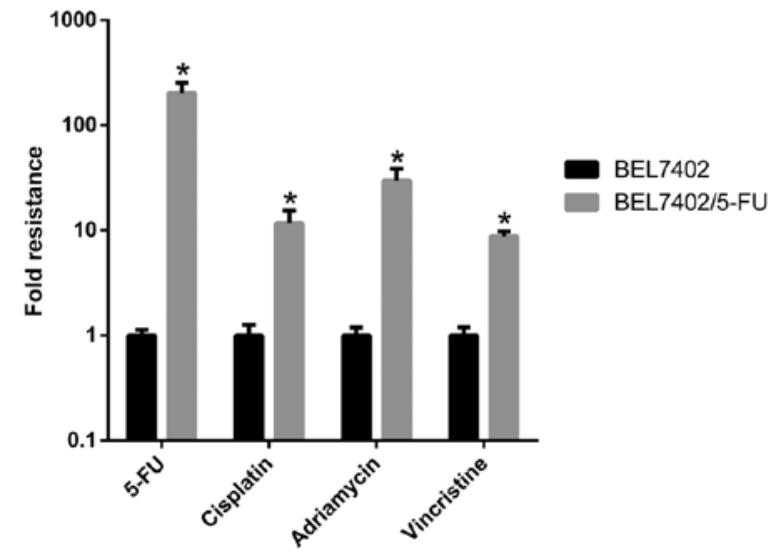

Figure 1. Biological characteristics of BEL7402/5-FU cells. The IC50 values for 5-FU, cisplatin, and adriamycin treatment in BEL7402/5-FU cells were 201.61-, 11.74- and 29.8-fold higher than they were in the BEL7402 cells, respectively. Bars show the standard deviation (SD). * $\mathrm{P} \leq 0.05$ compared to the control by a Student's t-test. IC50, half maximal inhibitory concentration.

The arithmetic product of the two parameters was generated as the IHC score value. All evaluations were performed by the same pathologist to maintain consistency.

Cell proliferation, migration and invasion assays. BEL7402 and HepG2 cells were transfected with negative control siRNA and AHSG siRNA sequences as previously mentioned. For the proliferation assay, transfected BEL7402 and HepG2 were added into 96 -well plates at a density of $1 \times 10^{3}$ cells/well, and the number of viable cells was monitored at regular intervals by WST- 8 . Cell migration and invasion assays were carried out in 24-well plates using polycarbonate membrane inserts (Cell Biolabs, Inc.) with $8 \mu \mathrm{m}$ pores. For the cell invasion assay, an additional uniform basement membrane matrix layer was coated on the upper surface of the chambers to obstruct non-invasive cells. Transfected cells were re-suspended with serum-free media at a concentration of $1.0 \times 10^{6}$ cells $/ \mathrm{ml}$ and plated into the polycarbonate membrane chambers. Medium containing $10 \%$ FBS was added to the bottom of each well. After $24-\mathrm{h}$ incubation at $37^{\circ} \mathrm{C}$, any cells on the surface of the chambers that had not migrated or invaded were removed. The migrated and invaded cells on the polycarbonate membrane were stained with cell stain solution (Cell Biolabs, Inc.), dissociated with extraction solution, and the optical density was quantified at $560 \mathrm{~nm}$.

Statistical analysis. The continuous variables in this study were presented as mean \pm standard deviation (SD). Statistical analysis of data in this study was conducted by SPSS Statistics 21 software. The IC50 values of each chemotherapeutic drug were calculated by the probit analysis (8). Intergroup significance tests were conducted using a Student's t-test and the data were considered statistically significant when $\mathrm{P}<0.05$.

\section{Results}

Property of MDR. The biological characteristics of BEL7402 and its MDR phenotype cell line BEL7402/5-FU have been previously described (9). The state of the cells was slightly different from that of the previous study, since they were of a 
Table I. IC50 values $(\mathrm{mg} / \mathrm{l})$ for selected reagents (mean $\pm \mathrm{SD})$.

\begin{tabular}{lrrrr}
\hline Reagent & BEL7402 & BEL7402/5-FU & Fold resistance relative to BEL7402 & P-value \\
\hline 5-FU & $3.46 \pm 0.31$ & $697.57 \pm 52.88$ & 201.61 & $<0.05$ \\
Cisplatin & $8.92 \pm 0.46$ & $104.68 \pm 3.720$ & 11.74 & $<0.05$ \\
Adriamycin & $5.82 \pm 0.39$ & $172.74 \pm 9.180$ & 29.68 & $<0.05$ \\
Vincristine & $10.83 \pm 0.96$ & $94.77 \pm 5.190$ & 8.75 & $<0.05$ \\
\hline
\end{tabular}

IC50, half maximal inhibitory concentration.

A

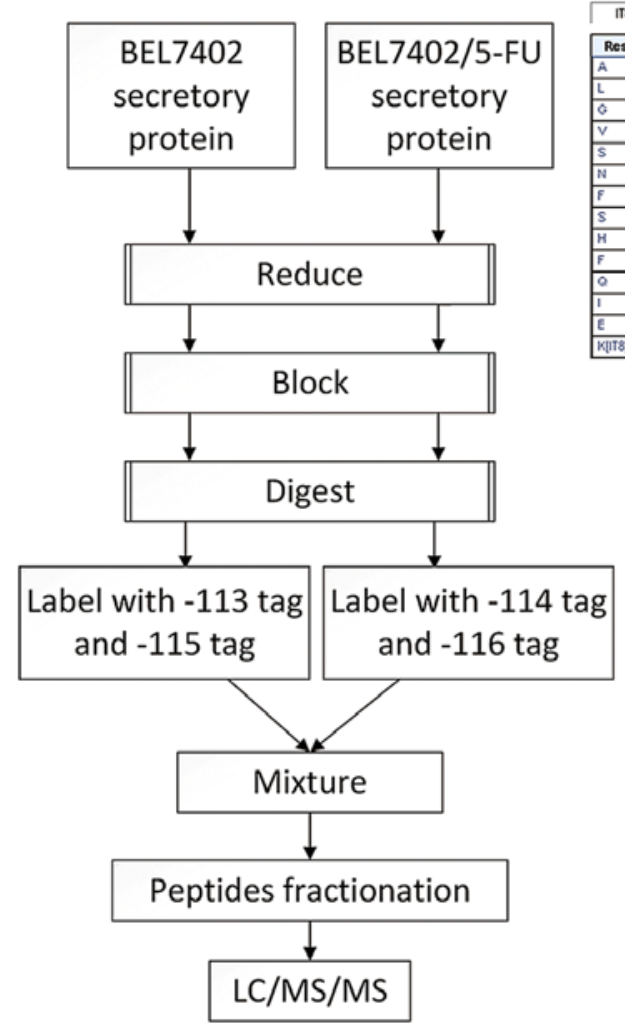

B

Fragmentation evidence for peptide

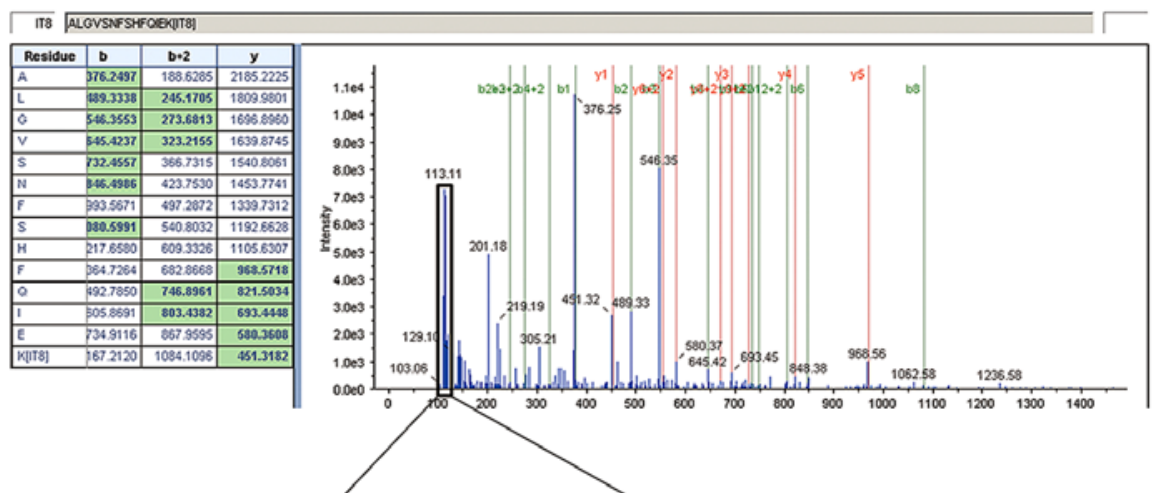

Figure 2. (A) Flow chart of iTRAQ proteomics approach. (B) Representative MS/MS spectrum showing the peptides from AKR (peptide sequence: ALGVSNFSHFQIEK). Secretory proteins of BEL7402 cells were labeled with iTRAQ 113 and 115 tags, and secretory proteins of the BEL7402/5-FU cells were labeled with iTRAQ 114 and 116 tags. Therefore, the ratio of 114:113 and 116:115 indicated the relative abundance of AKR in the secretome of BEL7402/5-FU compared with BEL7402. iTRAQ, isobaric tags for relative and absolute quantification; AKR, aldo-keto reductase.

different generation. Following the protocol mentioned above, dose-response relationships for 5 -Fu, cisplatin and adriamycin were obtained and analyzed by SPSS software using the probit model, thereby determining the IC50 values. As is shown in Table I, the IC50 values of 5-Fu for BEL7402 and BEL7402/5-FU were 3.46 \pm 0.31 and $697.57 \pm 52.88$, respectively. Thus, the resistance to 5-Fu of BEL7402/5-FU was 201.61-fold higher than that for BEL7402 (Fig. 1). Differences were also observed following treatment with cisplatin, adriamycin, and VCR, which amounted to 11.74-, 29.68- and 8.75-fold higher in BEL7402/5-FU cells, respectively (Table I and Fig. 1). The results indicated that BEL7402/5-FU was resistant to several types of chemotherapeutic drugs, and served as a typical model in the MDR study of HCC.

iTRAQ-based MS analysis. Secretory protein samples were enriched from a cell culture medium of the human BEL7402 HCC cell line and its MDR cell line BEL7402/5-FU, and subjected to iTRAQ-based MS analysis after being labeled with iTRAQ tags. A brief flowchart of the quantitative proteomic approach using isobaric labeling is presented in Fig. 2A. A duplicate of each sample was created to increase confidence in the result, and protein samples were labeled as follows: BEL7402, 113 and 115; BEL7402/5-FU, 114 and 116. 
Table II.Partial list of proteins identified to be expressed at different levels between the secretome of BEL 7402 and BEL7402/5-FU cells by iTRAQ analysis.

114:113 PVal 114:113 116:115 PVal 116:115

\begin{tabular}{|c|c|c|c|}
\hline No. & Accession & Gene symbol & Protein \\
\hline \multicolumn{4}{|c|}{ Top 30 upregulated proteins in HCC MDR cell line BEL7402/5-FU } \\
\hline 1 & IPI:IPI00953689.1 & AHSG & $\alpha$-2-HS-glycoprotein \\
\hline 2 & IPI:IPI00106646.1 & SDF4 & $\begin{array}{l}\text { Isoform } 1 \text { of } 45 \mathrm{kDa} \\
\text { calcium-binding protein }\end{array}$ \\
\hline 3 & IPI:IPI00645038.1 & ITIH2 & Uncharacterized protein \\
\hline 4 & IPI:IPI00006114.5 & SERPINF1 & $\begin{array}{l}\text { Pigment epithelium-derived } \\
\text { factor }\end{array}$ \\
\hline 5 & IPI:IPI00940698.4 & FAT1 & Protocadherin fat 1 \\
\hline 6 & IPI:IPI00759659.1 & GOLM1 & $\begin{array}{l}\text { Isoform } 2 \text { of Golgi } \\
\text { membrane protein } 1\end{array}$ \\
\hline 7 & IPI:IPI00016677.1 & ANGPT1 & Angiopoietin-1 \\
\hline 8 & IPI:IPI01021088.1 & $\mathrm{C} 4 \mathrm{~A}$ & Uncharacterized protein \\
\hline 9 & IPI:IPI00022443.1 & AFP & $\alpha$-fetoprotein \\
\hline 10 & IPI:IPI00298971.1 & VTN & Vitronectin \\
\hline 11 & IPI:IPI00783987.2 & C3 & $\begin{array}{l}\text { Complement C3 } \\
\text { (fragment) }\end{array}$ \\
\hline 12 & IPI:IPI00296099.6 & THBS1 & Thrombospondin-1 \\
\hline 13 & IPI:IPI00289501.2 & VGF & $\begin{array}{l}\text { Neurosecretory protein } \\
\text { VGF }\end{array}$ \\
\hline 14 & IPI:IPI00012501.1 & REG4 & $\begin{array}{l}\text { Isoform } 1 \text { of regenerating } \\
\text { islet-derived protein } 4\end{array}$ \\
\hline 15 & IPI:IPI00967014.1 & LMAN2 & Uncharacterized protein \\
\hline 16 & IPI:IPI00009450.1 & KITLG & Isoform 1 of kit ligand \\
\hline 17 & IPI:IPI00410714.5 & HBA1 & Hemoglobin subunit $\alpha$ \\
\hline 18 & IPI:IPI00008894.2 & CPA4 & Carboxypeptidase A4 \\
\hline 19 & IPI:IPI00001922.1 & ST14 & $\begin{array}{l}\text { Suppressor of tumorigenicity } \\
14 \text { protein }\end{array}$ \\
\hline 20 & IPI:IPI00022608.2 & SORL1 & Sortilin-related receptor \\
\hline 21 & IPI:IPI00021267.2 & EPHA2 & Ephrin type-A receptor 2 \\
\hline 22 & IPI:IPI00009054.1 & BMP1 & $\begin{array}{l}\text { Isoform BMP1-3 of bone } \\
\text { morphogenetic protein } 1\end{array}$ \\
\hline 23 & IPI:IPI00003590.2 & QSOX1 & $\begin{array}{l}\text { Isoform } 1 \text { of } \\
\text { sulfhydryl oxidase } 1\end{array}$ \\
\hline 24 & IPI:IPI00009123.2 & NUCB2 & Isoform 1 of nucleobindin- 2 \\
\hline 25 & IPI:IPI00942173.2 & EXT2 & exostosin-2 isoform 1 \\
\hline 26 & IPI:IPI00026530.4 & LMAN1 & Protein ERGIC-53 \\
\hline 27 & IPI:IPI00020557.2 & LRP1 & $\begin{array}{l}\text { Prolow-density lipoprotein } \\
\text { receptor-related protein } 1\end{array}$ \\
\hline 28 & IPI:IPI00299594.2 & NRP1 & Isoform 1 of neuropilin-1 \\
\hline 29 & IPI:IPI00290089.5 & CDH17 & Cadherin-17 \\
\hline 30 & IPI:IPI00294004.1 & PROS1 & $\begin{array}{l}\text { Vitamin K-dependent } \\
\text { protein } S\end{array}$ \\
\hline
\end{tabular}

$\begin{array}{rrrr}25.118860240 & 6.05295 \mathrm{E}-05 & 45.289760590 & 0.002399602 \\ 16.595869060 & 5.12532 \mathrm{E}-09 & 11.271969800 & 0.001372787 \\ & & & \\ 14.454400060 & 6.93501 \mathrm{E}-06 & 23.120649340 & 3.04468 \mathrm{E}-06 \\ 12.359470370 & 0.026673960 & 6.792037010 & 0.042003460 \\ & & & \\ 11.587770460 & 0 & 15.416999820 & 0 \\ 11.587770460 & 9.60308 \mathrm{E}-10 & 11.376270290 & 5.92455 \mathrm{E}-10 \\ & & & \\ 11.481539730 & 0.024134710 & 13.551890370 & 0.021998320 \\ 11.376270290 & 9.45976 \mathrm{E}-05 & 5.970353127 & 0.007338601 \\ 9.375619888 & 0.012612420 & 16.292959210 & 0.006130165 \\ 8.709635735 & 0.000305956 & 10.280159950 & 0.000606790 \\ 7.943282127 & 0.004883054 & 4.920394897 & 0.000529424 \\ 7.655965805 & & & \\ 7.585775852 & 0.008657940 & 12.70573997 & 0.001204193 \\ & & & \\ 7.244359016 & 1.23777 \mathrm{E}-05 & 12.24615955 & 0.029967191 \\ 4.655860901 & 6.72307 \mathrm{E}-09 & 8.629785538 & 6.33739 \mathrm{E}-10 \\ 4.570881844 & 6.37751 \mathrm{E}-06 & 5.701642990 & 1.09191 \mathrm{E}-06\end{array}$

Top 30 downregulated proteins in HCC MDR cell line BEL7402/5-FU

1 IPI.IPI00105407.2 AKR1B10 Aldo-keto reductase family 1 member B10

2 IPI:IPI00018534.4 HIST1H2BL Histone H2B type 1-L

3 IPI:IPI00296183.8 ALDH3A1 Aldehyde dehydrogenase,

4 IPI:IPI00643623.1 LCN2 dimeric NADP-preferring

Neutrophil gelatinase-associated lipocalin

$5 \quad$ IPI:IPI01021414.1 KRT8 Uncharacterized protein

6 IPI:IPI00031420.3 UGDH
0.037325021

0

$0.080167808 \quad 2.99352 \mathrm{E}-06$ $0.092896640 \quad 2.67555 \mathrm{E}-07$

0.107646503

0.003038801

$0.107646503 \quad 5.26549 \mathrm{E}-06$

$0.114815399 \quad 1.34732 \mathrm{E}-05$
$0.034673680 \quad 0$

$0.115877703 \quad 1.0221 \mathrm{E}-050$ $0.288403213 \quad 3.1888 \mathrm{E}-070$

$0.029107170 \quad 6.29562 \mathrm{E}-09$ 
Table II. Continued. Partial list of proteins identified to be expressed at different levels between the secretome of BEL7402 and BEL7402/5-FU cells by iTRAQ analysis.

\begin{tabular}{llllll}
\hline No. Accession & Gene symbol $\quad$ Protein & $114: 113$ & PVal 114:113 & $116: 115$ & PVal 116:115
\end{tabular}

Top 30 downregulated proteins in HCC MDR cell line BEL7402/5-FU

$\begin{array}{llll}7 & \text { IPI:IPI00453473.6 } & \text { HIST2H4B } & \text { Histone H4 } \\ 8 & \text { IPI:IPI00012069.1 } & \text { NQO1 } & \text { NAD(P)H dehydrogenase }\end{array}$

9 IPI:IPI00026154.3 PRKCSH

10 IPI:IPI00220362.5 HSPE1

11 IPI:IPI00217467.3 HIST1H1E

12 IPI:IPI01025667.1 SERPINA3

\section{IPI:IPI00029733.1 AKR1C1}

14 IPI:IPI00010182.4 DBI

15 IPI:IPI00291006.2 MDH2

16 IPI:IPI00983296.2 ACLY

17 IPI:IPI00917605.1 CYCS

18 IPI:IPI01018179.1 ILF3

19 IPI:IPI00219029.3 GOT1

IPI:IPI00007427.2 IPI:IPI00792375.1

AGR2 IPI:IPI00419585.9 PPIA

23 IPI:IPI00020017.1 C10orf116

IPI:IPI00027223.2 IDH1

25 IPI:IPI00215901.1 AK2

26 IPI:IPI00000874.1 PRDX1

27 IPI:IPI00093057.6 CPOX

28 IPI:IPI00022977.1 CKB

29 IPI:IPI00401264.5 ERP44

30 IPI:IPI00979574.1 MDK

$\mathrm{NAD}(\mathrm{P}) \mathrm{H}$ dehydrogenase (quinone) 1

cDNA FLJ59211,

highly similar to glucosidase 2 subunit $\beta$ $10 \mathrm{kDa}$ heat shock protein, mitochondrial

Histone H1.4

cDNA FLJ35730 fis, clone TESTI2003131, highly similar to $\alpha$-1-antichymotrypsin

Aldo-keto reductase family 1 member $\mathrm{C} 1$ Isoform 1 of Acyl-CoA-binding protein Malate dehydrogenase, mitochondrial

Uncharacterized protein Uncharacterized protein Isoform 4 of interleukin enhancer-binding factor 3 cytoplasmic

AGR2

Peptidyl-prolyl cis-trans

isomerase $\mathrm{A}$ transcript 2 protein

Isocitrate dehydrogenase

(NADP) cytoplasmic

Isoform 1 of

Adenylate kinase 2,

mitochondrial

Peroxiredoxin-1

Coproporphyrinogen-III

oxidase, mitochondrial

Creatine kinase B-type

Endoplasmic reticulum resident protein 44

Midkine
Aspartate aminotransferase,

0.134276494

0.149968505

3.82621E- 08

0.190546095

5.78951E-07

0.162929595

$1.14058 \mathrm{E}-11$

0.134276494

9.80593E-11

0.299226493

0.197696999

0.002608684

0.218776196

0.027179141

0.220800504

0.000691467

0.349945188

0.006769219

0.222843498

0.000235783

0.154170096

9.59783E-05

Fructose-bisphosphate aldolase

Adipose most abundant gene

$$
\begin{aligned}
& 0 \\
& 0 \\
& 0 \\
& 0 \\
& 0 \\
& 0 \\
& 0 \\
& 0 \\
& 0
\end{aligned}
$$

$\begin{array}{lllll}0.224905506 & 0.008086700 & 0.148593605 & 0.000119699\end{array}$

$\begin{array}{lllll}0.231206506 & 0.000107410 & 0.465586096 & 0.002986300\end{array}$

$0.233345807 \quad 9.86183 \mathrm{E}-06 \quad 0.235504895 \quad 0.000950984$

$\begin{array}{llll}0.233345807 & 1.51074 \mathrm{E}-09 & 0.288403213 & 1.29354 \mathrm{E}-10\end{array}$

$\begin{array}{lllll}0.235504895 & 0.005656152 & 0.158489302 & 0.003914892\end{array}$

$\begin{array}{lllll}0.263026804 & 0.000180477 & 0.444631308 & 0.004805207\end{array}$

$0.267916799 \quad 3.46966 \mathrm{E}-05 \quad 0.263026804 \quad 1.10814 \mathrm{E}-05$

$\begin{array}{lllll}0.267916799 & 1.02068 \mathrm{E}-05 & 0.452897608 & 0.010829240\end{array}$

$\begin{array}{lllll}0.275422901 & 0.035917360 & 0.233345807 & 1.75565 \mathrm{E}-05\end{array}$

$\begin{array}{lllll}0.275422901 & 0.000102973 & 0.487528503 & 0.000280568\end{array}$

$\begin{array}{lllll}0.288403213 & 0.000386034 & 0.380189389 & 0.000680905\end{array}$

$0.299226493 \quad 3.05757 \mathrm{E}-06 \quad 0.401790798 \quad 2.68666 \mathrm{E}-05$

$0.301995188 \quad 6.4206 \mathrm{E}-05 \quad 0.263026804 \quad 0.004157949$

$\begin{array}{llll}0.313328594 & 3.14493 \mathrm{E}-08 & 0.461317599 & 7.03658 \mathrm{E}-05\end{array}$

$\begin{array}{lllll}0.316227794 & 0.002345311 & 0.448745400 & 0.012942430\end{array}$

$\begin{array}{llll}0.322106898 & 2.06405 \mathrm{E}-05 & 0.291071713 & 1.09439 \mathrm{E}-07\end{array}$

$\begin{array}{lllll}0.325087309 & 0.00020159 & 0.334194988 & 0.000275739\end{array}$

$\begin{array}{llll}0.328095287 & 0.01038363 & 0.428548515 & 0.009072857\end{array}$
Thus, the relative abundance of proteins from BEL7402/5-FU cells with respect to proteins from BEL7402 cells was revealed as the iTRAQ ratios 114:113 and 116:115. The isobaric-labeled peptides were analyzed by LC/MS/MS, searched for in the IPI database, and identified with ProteinPilot software. By searching the human IPI database under the ProteinPilot algorithm, 1,780 unique proteins were identified with $95 \%$ confidence. Considering the technical variations of the method and statistical analysis in the relative quantification analysis, and in order to reduce false positives and increase accuracy, stricter cut-off points were imposed when dividing the identified proteins. Proteins with a ratio $>1.5$ or $<0.5$ were classified as upregulated or downregulated (10). In total, 279 differentially expressed proteins were filtrated, of which 131 proteins were highly expressed in BEL7402/5-FU relative to its parental cell line, while 56 proteins were underexpressed. Table II 
A

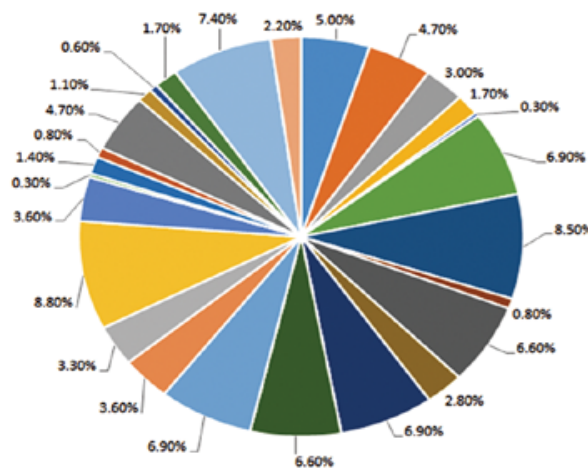

B

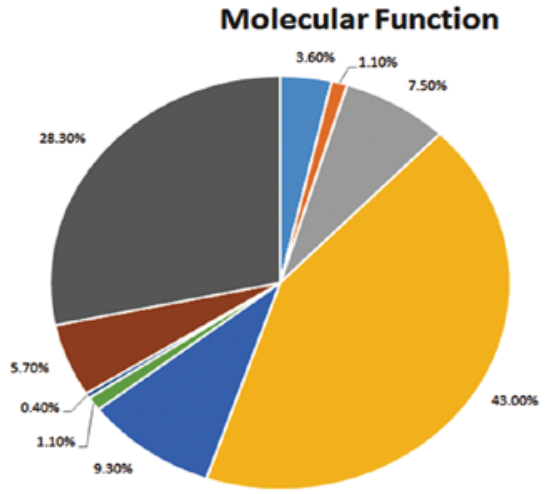

C Biological Process

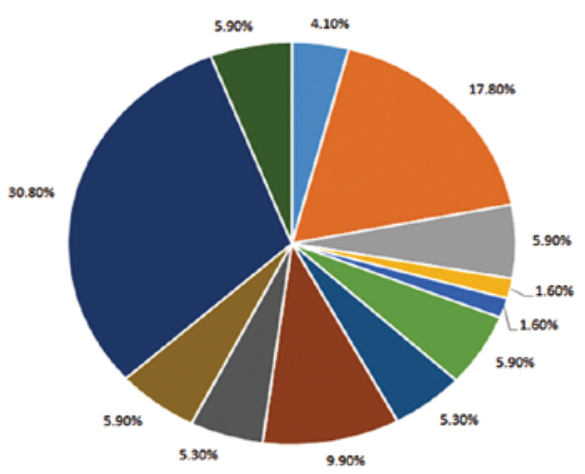

D Cellular Component

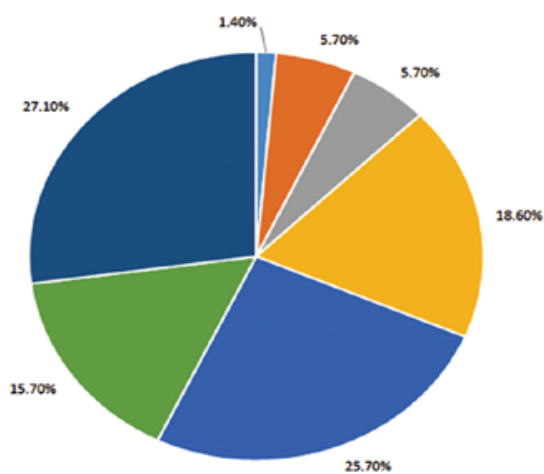

- extracellular matrix protein (PC00102) $5.00 \%$

- protease (PCO0190) $4.70 \%$

- cytoskeletal protein (PCO0085) 3.00\%

- transporter (PCO0227) 1.70\%

- transmembrane receptor regulatory/adaptor protein (PC00226) 0.30\%

- transferase (PCO0220) 6.90\%

- oxidoreductase (PC00176) 8.50\%

- Iyase (PC00144) 0.80\%

- cell adhesion molecule (PCO0069) 6.60\%

- ligase (PCO0142) 2.80\%

- nucleic acid binding (PCO0171) 6.90\%

- signaling molecule (PCO0207) 6.60\%

- enzyme modulator (PCO0095) 6.90\%

" calcium-binding protein (PCO0060) $3.60 \%$

" defense/immunity protein (PCO0090) 3.30\%

" hydrolose (PCO0121) 8.80\%

- transfer/carrier protein (PCO0219) 3.60\%

- membrane traffic protein (PCO0150) $0.30 \%$

- phosphatase (PCO0181) 1.40\%

- transcription factor (PCO0218) 0.80\%

- chaperone (PCO0072) $4.70 \%$

- cell junction protein (PCO0070) 1.10\%

- structural protein (PCO0211) $0.60 \%$

- kinase (PCO0137) 1.70\%

- receptor (PC00197) 7.40\%

"I isomerase (PC00135) $2.20 \%$

- transporter activity (GO:0005215) $3.60 \%$

- translation regulator activity (GO:0045 182) 1.10\%

- enzyme regulator activity (GO:0030234) 7.50\%

" catalytic activity (GO:0003824) 43.00\%

- receptor activity (GO:0004872) 9.30\%

- nucleic acid binding transcription factor activity (GO:0001071) 1.10\%

- antioxidant activity (GO:0016209) 0.40\%

- structural molecule activity (GO:0005198) 5.70\%

- binding (GO:0005488) 28.30\%
- cellular component organization or biogenesis (GO-0071840) 4.10\%

- cellular process (GO:0009987) 17.80\%

- localization (GO:0051179) 5.90\%

= apoptotic process (GO:0006915) 1.60\%

- reproduction (GO:0000003) 1.60\%

- biological regulation (GO:0065007) 5.90\%

- response to stimulus (GO:0050896) 5.30\%

- developmental process (60:0032502) 9.90\%

- multicellular organismal process (GO:0032501) 5.30\%

- biological adhesion (GO:0022610) 5.90\%

- metabolic process (GO:0008152) 30.80\%

- immune system process (GO:0002376) 5.90\%

\author{
- cell Junction (GO:0030054) 1.40\% \\ - membrane (GO:0016020) 5.70\% \\ - macromolecular complex (GO:0032991) 5.70\% \\ = extracellular matrix (GO:0031012) 18.60\% \\ - cell part (GO:0044464) 25.70\% \\ - organelle (GO:0043226) 15.70\% \\ - extracellular region (GO:0005576) 27.10\%
}

Figure 3. Categories of 279 differentially expressed proteins clustered according to protein class, molecular function, biological process and cellular component by the PANTHER system. 


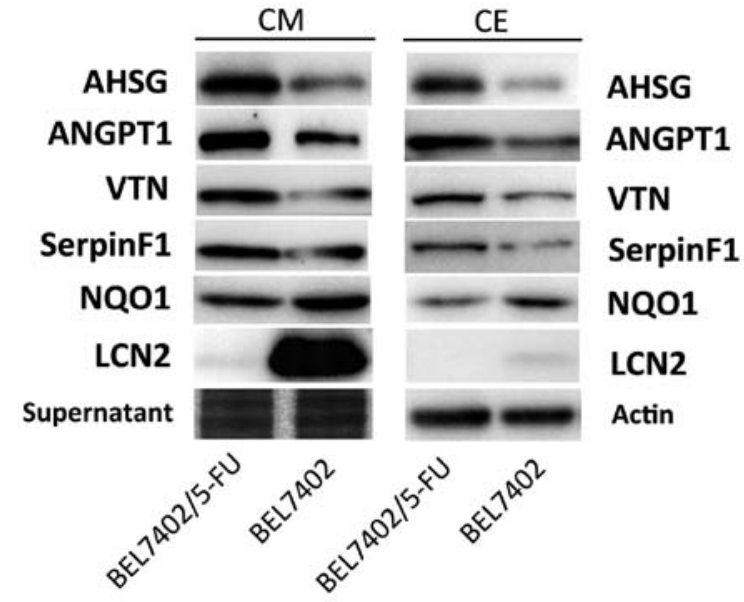

Figure 4. Validation of the dysregulated secretory proteins in BEL7402/5-FU cells with respect to the BEL402 cells by western blot analysis. Compared to the expression in the parental BEL7402 cell line, AHSG, ANGPT1, VTN and SerpinF1 were upregulated in the secretory protein $(\mathrm{CM})$ and total cytoplasmic protein (CE) in BEL7402/5-FU cells, while NQO1 and LCN2 were downregulated. AHSG, $\alpha$-2-HS-glycoprotein; ANGPT1, angiopoietin 1; VTN, vitronectin; NQO1, NAD(P)H dehydrogenase (quinone) 1; LCN2, lipocalin-2.

shows the top 30 upregulated and downregulated proteins in BEL7402/5-FU cells compared to BEL7402 cells. Of the downregulated proteins, aldo-keto reductase (AKR) (peptide sequence: ALGVSNFSHFQIEK) ranks in the top 30, and its MS/MS spectrum and relative abundance by iTRAQ ratio 116:115 and 114:113 are shown in Fig. 2B.

Protein classification by the PANTHER classification system. To achieve a preview of the profile of the 279 differentially expressed proteins, the proteins were classified by the PANTHER classification system (http://www.pantherdb.org) according to protein class, cellular component, molecular function and biological process (Fig. 3). The differentially expressed proteins were various and divided into 28 classes, but mainly comprise nucleic acid binding (12.9\%), hydrolase $(11.7 \%)$, enzyme modulator $(6.8 \%)$ and signaling molecule (6.1\%) proteins (Fig. 3A). There were 10 molecular function categories, including catalytic activity (38.8\%) and binding (31.1\%) (Fig. 3B). The identified proteins participate in a range of biological processes, including metabolic processes (33.1\%) and cell processes (17.9\%) (Fig. 3C).

Validation of differentially expressed proteins. By studying protein classification and screening the relative abundance of proteins through the iTRAQ approach, the most significantly dysregulated proteins, AHSG, ANGPT1, VTN, SerpinF1, NQO1 and LCN2 were further validated. Western blotting was performed as described above to validate the identified differentially expressed proteins. The expression of AHSG, ANGPT1, VTN, SerpinF1, NQO1 and LCN2 in the conditioned medium and cell lysis product of BEL7402 and BEL7402/5-FU cells is shown in Fig. 4. The abundance of proteins AHSG, ANGPT1, VTN and SerpinF1 in secretory protein and total cytoplasmic protein were obviously higher in the BEL7402/5-FU than in BEL7402 cells, while NQO1 and LCN2 were downregulated. Thus, the results of immunoblotting were highly coincidental with the mass spectrum analysis.

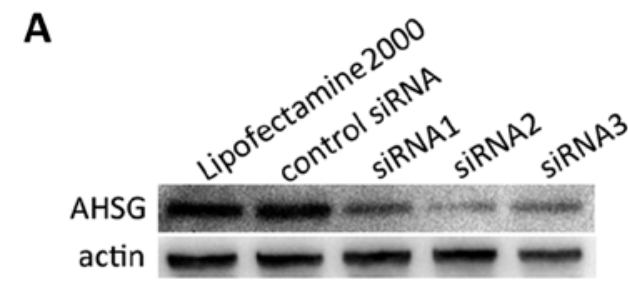

B

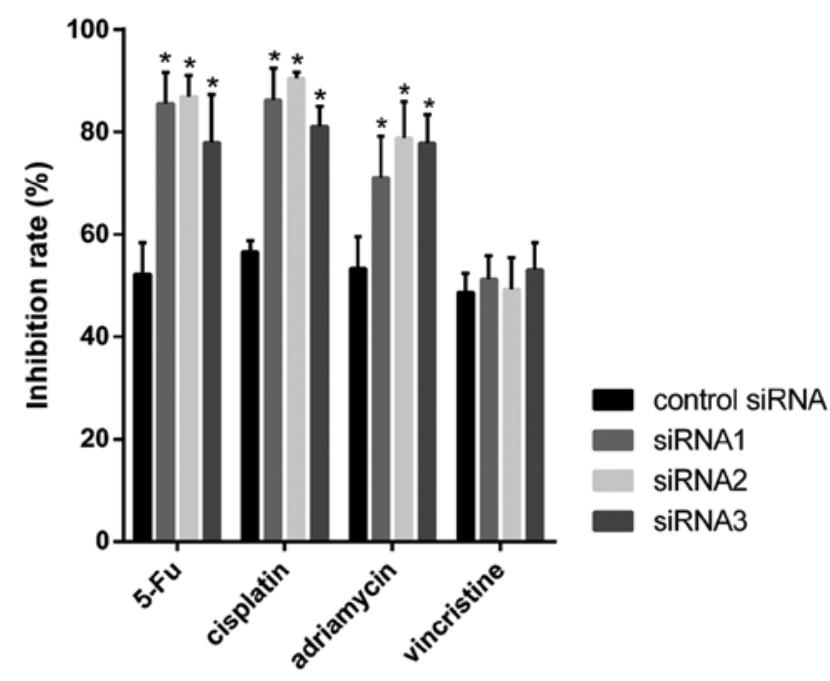

Figure 5. Effects of AHSG-knockdown on the responses to chemotherapeutic drugs of BEL7402/5-FU cell line. (A) Western blot analysis showed that the expression of AHSG in BEL7402/5-FU cells was significantly reduced by AHSG-specific siRNA sequence transfection, whereas it was not significantly suppressed by control siRNA or transfection reagent alone. (B) Suppression of AHSG expression in BEL7402/5-FU cells enhanced the sensitivity to 5-FU, cisplatin and adriamycin, with a significantly increased inhibition rate. Bars show the standard deviation (SD). ${ }^{*} \mathrm{P} \leq 0.05$ compared to the control by a Student's t-test. AHSG, $\alpha$-2-HS-glycoprotein.

The relevance of AHSG to MDR. To study the relevance of AHSG upregulation to the MDR phenomenon in the BEL7402/5-FU cell line, three specific siRNA sequences were employed to knock down AHSG expression in BEL7402/5-FU cells. By western blotting, AHSG expression in specific siRNA-transfected BEL7402/5-FU cells were proven to have been effectively silenced (Fig. 5A). To assess the relationship between AHSG and MDR, BEL7402/5-FU cells were treated with the aforementioned anticancer drugs for 2 days with their IC50 concentration after being transfected with specific siRNA sequences for $48 \mathrm{~h}$. Fig. 5B shows that the inhibition rate of anticancer drugs $5-\mathrm{Fu}$, cisplatin, adriamycin and VCR on AHSG-knockdown BEL7402/5-FU cells was higher, compared with negative control. IC50 values of these drugs to AHSG-knockdown cells are detailed in Table III, showing that IC50 values of $5-\mathrm{Fu}$, cisplatin and adriamycin were markedly decreased in AHSG-knockdown BEL7402/5-FU cells than negative control. The result suggested that suppression of AHSG minimizes BEL7402/5-FU resistance to several chemotherapeutic drugs, which, in turn, indicated that AHSG may contribute to the MDR phenomenon in the cell line. Furthermore, through FCM detection, we found that AHSG-knockdown has no effect on the apoptosis of BEL7402/5-FU under the pressure of chemotherapeutic drugs (data not shown). 
A
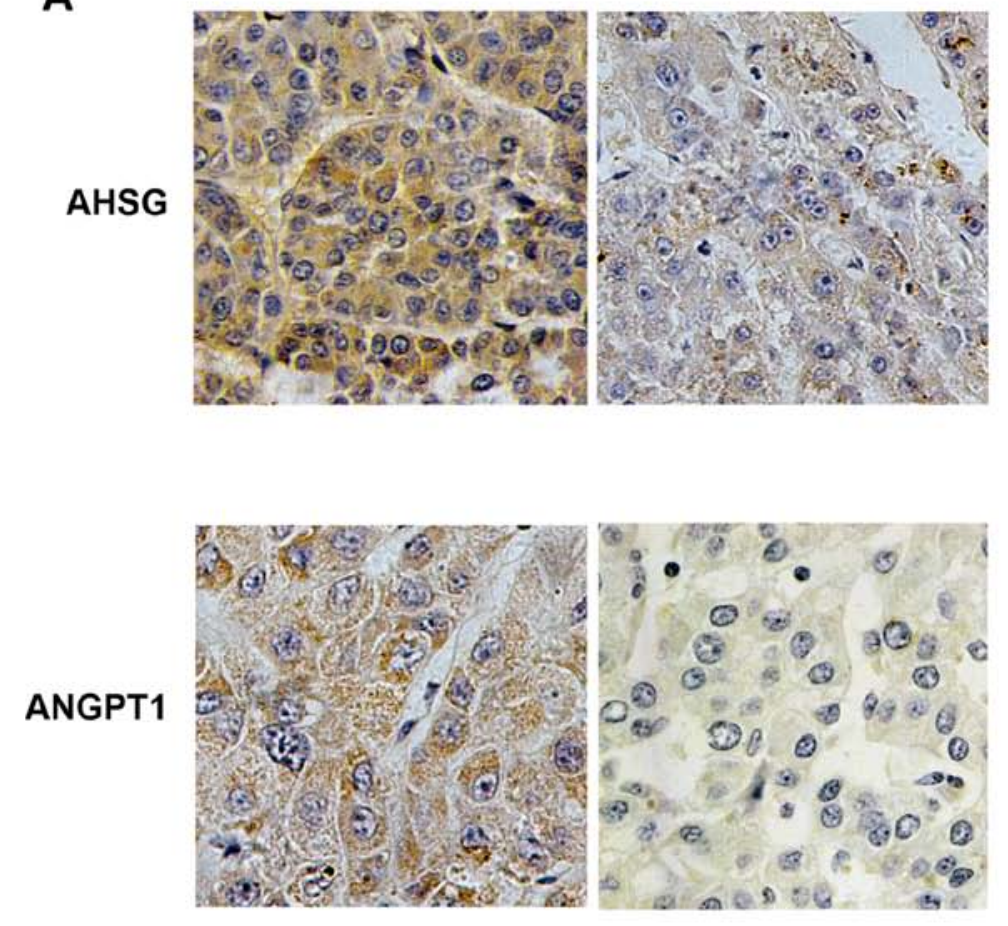

VTN

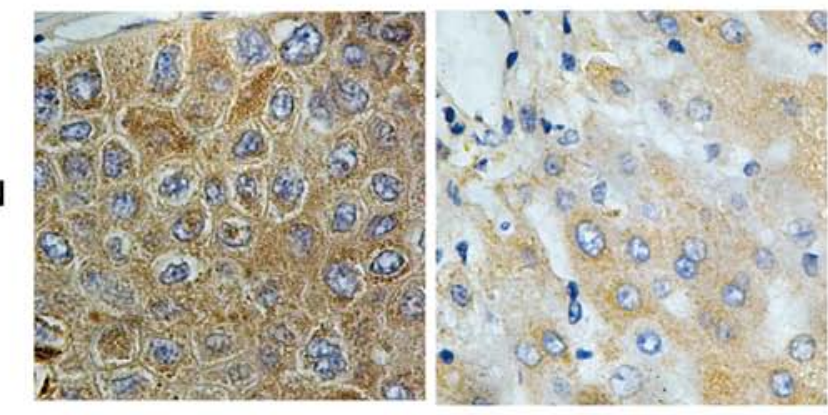

LCN2

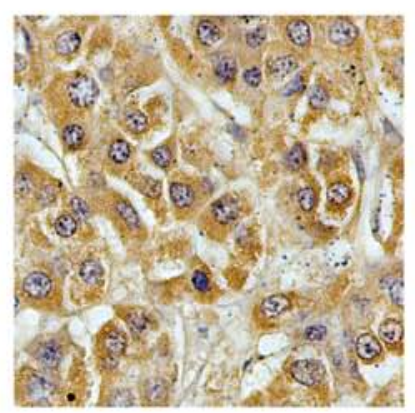

HCC tissue
B
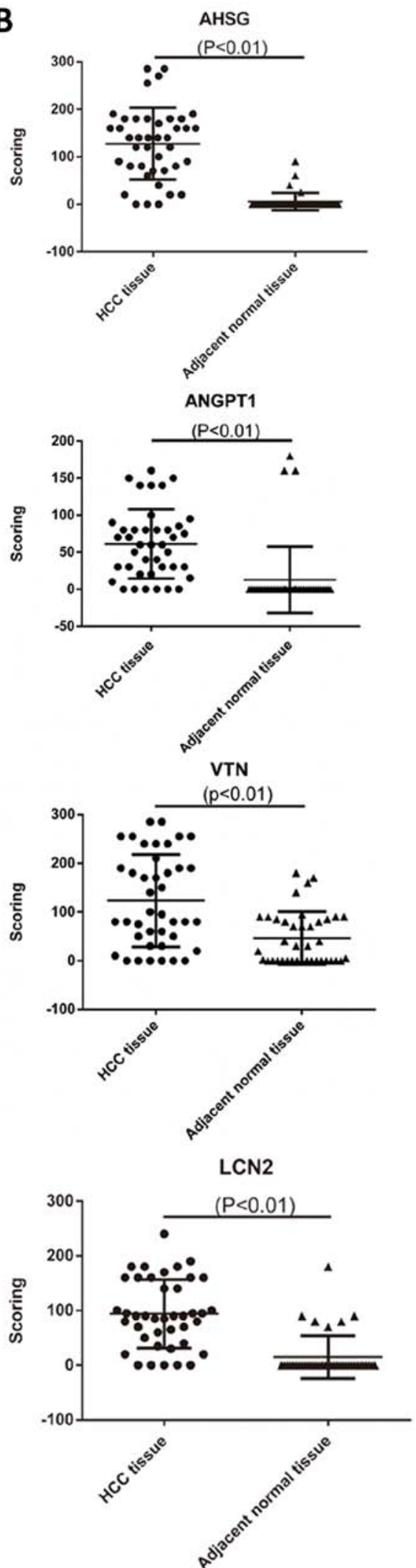

Figure 6. Validation of AHSG, ANGPT1, VTN and LCN2 overexpression in HCC tissues by tissue microarrays. (A) Representative images of IHC staining of AHSG, ANGPT1, VTN and LCN2 in HCC tissues and the adjacent normal tissues. (B) IHC score values of AHSG, ANGPT1, VTN and LCN2 were higher in NPC tissues than in adjacent normal tissues. AHSG, $\alpha-2$-HS-glycoprotein; ANGPT1, angiopoietin 1; VTN, vitronectin; LCN2, lipocalin-2; IHC, immunohistochemistry.

Association of dysregulated proteins with clinical HCC. The selected differentially expressed proteins in the present study have been reported be linked to tumor development and progression in several types of cancer (11-14). However, 
Table III. IC50 values (mg/l) for selected reagents after siRNA treatment (mean $\pm \mathrm{SD})$.

\begin{tabular}{lrrrr}
\hline Treatment & Control siRNA & \multicolumn{1}{c}{ siRNA-39 } & siRNA-40 & siRNA-41 \\
\hline $5-\mathrm{Fu}$ & $677.13 \pm 52.88$ & $332.57 \pm 30.20$ & $373.32 \pm 31.21$ & $248.20 \pm 19.58$ \\
Cisplatin & $106.17 \pm 5.110$ & $62.32 \pm 4.310$ & $60.15 \pm 6.500$ & $42.67 \pm 3.940$ \\
Adriamycin & $159.92 \pm 7.270$ & $100.67 \pm 12.31$ & $100.84 \pm 9.700$ & $86.42 \pm 4.400$ \\
Vincristine & $98.67 \pm 4.370$ & $102.97 \pm 12.28$ & $103.92 \pm 8.380$ & $112.68 \pm 10.77$ \\
\hline
\end{tabular}

IC50, half maximal inhibitory concentration.
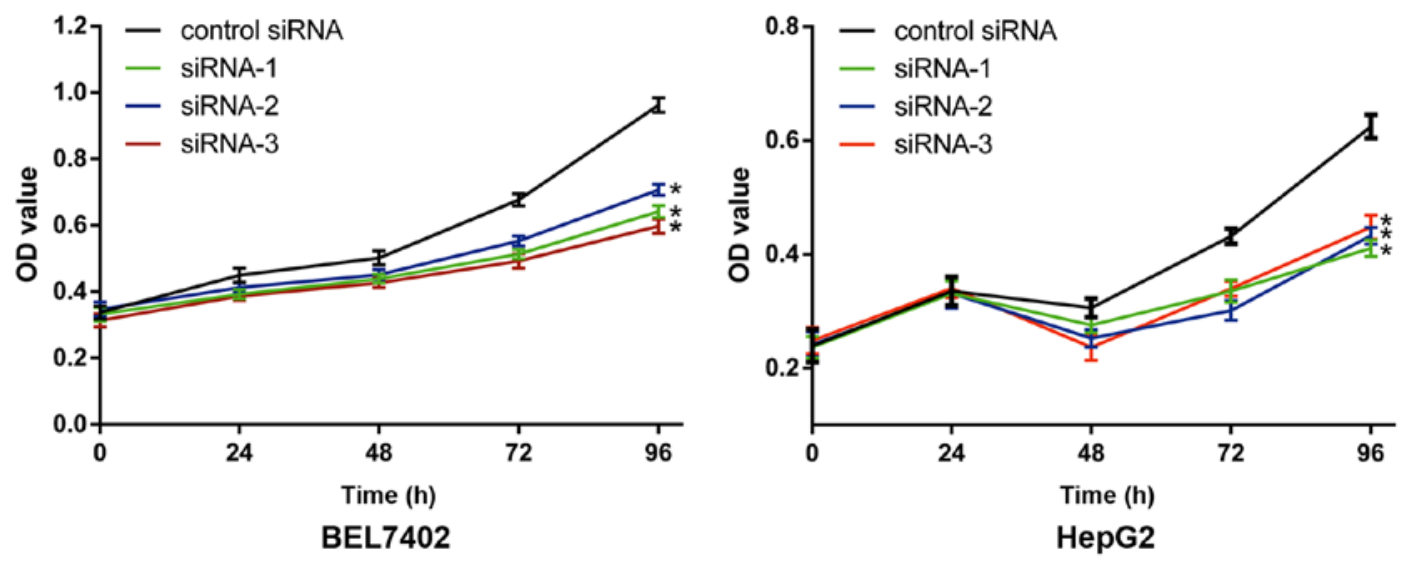

Figure 7. Influence of AHSG knockdown on cell proliferation in the BEL7402 and HepG2 cells. Suppression of AHSG in BEL7402 cells inhibits the speed of cell multiplication, which was also observed in HepG2 cells. Bars show the standard deviation (SD). "P $\leq 0.05$ as compared to the control using a Student's t-test. AHSG, $\alpha$-2-HS-glycoprotein.

their association with $\mathrm{HCC}$ is, by contrast, rarely reported. Moreover, chemoresistance phenotype is a common biological behavior in malignancy, while drug resistance may not be an isolated event in tumor development and progression. Thus, TMA containing $40 \mathrm{HCC}$ and adjacent tissues were employed for the immunohistochemical assay. Fig. 6A shows the expression of AHSG, ANGPT1, VTN, SerpinF1, NQO1, and LCN2 in HCC, and adjacent tissues. The proteins AHSG, ANGPT1 and VTN were significantly upregulated in HCC tissues compared to adjacent tissues, and the semi-quantitative analysis described above shows the differential expression visually, as well as the statistical significance (Fig. 6B). The differential expression of SerpinF1 and NQO1 was observed in only a few locations, and there was no significant difference in the expression of SerpinF1 and NQO1 between HCC tissue and the adjacent normal tissue. The IHC results of AHSG, ANGPT1 and VTN were coincident with MS/MS analysis of the MDR cell line, whereas LCN2, which was a markedly underexpressed protein in BEL7402/5-FU cells, was overexpressed in HCC tissues compared to adjacent tissues.

Effects of AHSG on HCC cell proliferation, migration and invasion. The experimental data on TMA, coupled with the known information on AHSG, suggests that AHSG may not only be connected with the MDR of HCC, but also contributes to the progression of the cancer. In light of this, the expression of AHSG in human HepG2 and BEL7402 HCC cell lines were knocked down by its specific siRNAs to prepare the cell proliferation, migration and invasion assays. By measuring the OD values following incubation with media containing WST-8 reagent, the relative amounts of viable cells at each specified time interval are shown in Fig. 7, showing that AHSG-knockdown cells, HepG2 and BEL7402, exhibited fewer cells in contrast to the control cells over time. In the cell migration and invasion assays, however, silencing of AHSG had little or no effect on the migration or invasion process of HepG2 and BEL7402 cells (data not shown).

\section{Discussion}

In the present study, the secretomic profiles of the human BEL7402 HCC cell line and its MDR cell line BEL7402/5-FU were comparatively analyzed by mass spectrum technology with the assistance of iTRAQ labels. Cancer secretomics focuses on proteins that are released by cancer cells and exist in the conditioned medium of cell lines or in the proximal body fluid of tumor tissue. Cancer secretome contains various proteins that have been shown to participate in numerous physiological and pathological processes such as cell signaling, immune defense, drug delivery, differentiation, cancer angiogenesis and invasion. Secretome is thus considered a potential source of biomarkers and worthy of investigation in this field (15). Studies have focused on mass spectrometry in recent years, identifying potential biomarkers in cancer cell secretome. In these studies, proximal body fluid is often employed because of its high correlativity with cancer tissues, for example pleural effusions in lung cancer $(16,17)$ and seminal plasma in prostate cancer (18). For most solid tumors, however, proximal body 
fluid is unavailable or excessively complex for MS analysis and the conditioned medium of cancer cells is, on this account, frequently utilized to delineate the cancer secretome. Primary cells from oral cavity squamous cell carcinoma (OSCC) and its adjacent non-tumor epithelium have thus been used in comparing their secretome profiles. As a result, 19 candidate proteins were eventually identified and the indications are that upregulation of THBS2 in OSCC may be associated with cancer progression (19). In a separate study, Gloghini et al (20) collected the secretomes of primary effusion lymphoma (PEL) cell lines and analyzed these cells using MLC-MS/MS and MALDI-TOF simultaneously. They found that S10A6, GRAA, CATA, ANM, PCBP2 and GSTK1 were strongly associated with PEL pathogenesis. Since no body fluid originates from HCC cells, the BEL7402 HCC cell line and its MDR phenotype were used as models in this study to investigate MDR pathogenesis. In total, 279 differentially expressed proteins were identified, of which 131 proteins were significantly upregulated in the secretome of the BEL7402/5-FU cell line and 56 proteins were downregulated.

Using western blot analysis, the expression of several identified proteins AHSG, ANGPT1, VTN, SerpinF1, NQO1 and LCN2 was validated at the same levels as those in the results of the quantitative proteomic analysis, revealing that iTRAQ-based quantitative proteomics was an efficient and powerful method in secretome analysis. BEL7402/5-FU cells were transfected with three specific siRNAs against AHSG, and their sensitivity to chemotherapeutic drugs was measured. The results show that the downregulation of AHSG may increase the response of the MDR cell line to several anticancer drugs, a finding that has not been previously reported in studies on HCC. AHSG, also known as fetuin-A, is a serum glycoprotein that is synthesized predominantly by hepatocytes. It has been proven to participate in functions such as bone tissue formation, brain development and endocytosis. Previous findings have demonstrated that, AHSG is highly relevant to insulin resistance and is pivotal in the genesis of diabetes (21-23), metabolic syndrome $(24,25)$ and non-alcoholic fatty liver disease (NAFLD) $(26,27)$. The elevation of serum AHSG levels increases the risk of type- 2 diabetes, since the protein AHSG specifically inhibits insulin receptor autophosphorylation (21) and serves as an endogenous ligand of toll-like receptor 4 (TLR4), which is crucial to the activation of an inflammatory pathway (22). AHSG is not only associated with metabolic disorders, and is also linked to several types of cancer. By blocking the binding of transforming growth factor- $\beta$ (TGF- $\beta$ ) to its receptors, AHSG modulates the TGF- $\beta$ signaling pathway which exerts bidirectional regulation effects on cancer progression $(28,29)$. As demonstrated in the IHC results, AHSG was highly expressed in HCC tissues with respect to their adjacent non-tumor tissues, and its downregulation was found to suppress the proliferation of human liver HepG2 and BEL7402 cancer cell lines, suggesting that the dysregulation of AHSG may be associated with the development of HCC. Moreover, we found that, by knocking down this expression, AHSG accelerates the migration process in HepG2 and BEL7402 but hardly affects cancer cell invasion. Associated with the link between the AHSG and TGF- $\beta$ pathway reported by many previous studies (28-30), the results of the present study suggest that the manner in which AHSG affects the tumor behaviors of HCC may depend on the degree it acts on the TGF- $\beta$ signaling pathway, a result that remains to be verified in future studies. Thus, through iTRAQ-based secretomic analysis, this study has shown that the upregulation of AHSG in the MDR cell line of HCC may be a predictive factor of chemotherapeutic drug resistance of $\mathrm{HCC}$, and it may also play a vital role in HCC progression.

Among the differentially expressed proteins, angiopoietin 1 (ANGPT1 or Ang1) is significantly overexpressed in BEL7402/5-FU with respect to its parental cell line BEL7402. Tissue microarrays showed that ANGPT1 was upregulated in HCC tissues as well, compared with their adjacent non-tumor tissues. ANGPT1 belongs to the angiopoietin family which modulates the angiogenesis processes, both physiologically and pathologically $(31,32)$ and is thus vital to the development of solid cancers (33-35). In addition, ANGPT1 is also reported as modulating multi-drug resistance in human glioma through Tie2 signaling by upregulating the ATP-binding cassette transporters (33). ANGPT1, therefore, may be a critical factor in oncogenesis and in the chemoresistance of HCC.

Dysregulated proteins including VTN, NQO1, LCN2 and SerpinF1 were identified by iTRAQ-based proteomic analysis and are involved in HCC chemoresistance. Of these, LCN2 showed a notable downregulation in the MDR cell line BEL7402/5-FU compared to BEL7402. LCN2 is derived from the lipocalin family and participates in numerous biological processes, including cell apoptosis and innate immune response when the organism is infected by a bacterium. It is also known to be overexpressed in several types of cancer, for example pancreatic (36), breast (37) and thyroid (38) cancer. It has also been reported that deficiency of LCN2 contributes to resistance to anticancer drugs of malignant glioma $(39,40)$. Although no study has verified the association of LCN2 and HCC chemoresistance, the relationship between LCN2 and the MDR mechanism of HCC should be further investigated.

HCC remains a threat for patients with cirrhosis caused by alcohol, hepatitis $\mathrm{B}$ or $\mathrm{C}$ virus. MDR appears to be a main obstacle to chemotherapy for advanced HCC patients. Ascertaining its mechanism may be useful in eradicating this obstacle. In the present quantitative secretomic study, 279 differentially expressed proteins, which may be associated with the MDR of BEL7402/5-FU, were identified, and the relevance of AHSG to MDR was then determined. Data in this study facilitate further investigation of the MDR phenomenon in $\mathrm{HCC}$, in order to ascertain the role of MDR.

\section{Acknowledgements}

This study was supported by the National Natural Science Foundation of China (no. 81171560, 30930082, 81171561, 30972584), the National Science and Technology Major Project of China (no. 2008ZX10002-006, 2012ZX1002007001, 2011ZX09302005, 2012ZX09303001-001, 2012ZX10002003).

\section{References}

1. Ferlay J, Soerjomataram I, Ervik M, Dikshit R, Eser S, Mathers C, Rebelo M, Parkin DM, Forman D and Bray F: GLOBOCAN 2012 v1.0, Cancer Incidence and Mortality Worldwide: IARC CancerBase No. 11 (Internet). International Agency for Research on Cancer, Lyon, France, 2013. http://globocan.iarc.fr. Accessed April 01, 2014. 
2. Ling V: Multidrug resistance: Molecular mechanisms and clinical relevance. Cancer Chemother Pharmacol 40 (Suppl): S3-S8, 1997.

3. Naito S, Yokomizo A and Koga H: Mechanisms of drug resistance in chemotherapy for urogenital carcinoma. Int J Urol 6: 427-439, 1999.

4. Pérez-Tomás R: Multidrug resistance: Retrospect and prospects in anti-cancer drug treatment. Curr Med Chem 13: 1859-1876, 2006.

5. Tanaka H, Kono E, Tran CP, Miyazaki H, Yamashiro J, Shimomura T, Fazli L, Wada R, Huang J, Vessella RL, et al: Monoclonal antibody targeting of $\mathrm{N}$-cadherin inhibits prostate cancer growth, metastasis and castration resistance. Nat Med 16 : $1414-1420,2010$

6. Soothill JS, Ward R and Girling AJ: The IC50: An exactly defined measure of antibiotic sensitivity. J Antimicrob Chemother 29: 137-139, 1992 .

7. Yang Y, Toy W, Choong LY, Hou P, Ashktorab H, Smoot DT, Yeoh KG and Lim YP: Discovery of SLC3A2 cell membrane protein as a potential gastric cancer biomarker: Implications in molecular imaging. J Proteome Res 11: 5736-5747, 2012.

8. Finney DJ: Probit analysis; a statistical treatment of the sigmoid response curve. 1st edition. Macmillan, Oxford, 256, 1947.

9. Tong SW, Yang YX, Hu HD, An X, Ye F, Hu P, Ren H, Li SL and Zhang DZ: Proteomic investigation of 5-fluorouracil resistance in a human hepatocellular carcinoma cell line. J Cell Biochem 113: $1671-1680,2012$

10. Yang Y, Lim SK, Choong LY, Lee H, Chen Y, Chong PK, Ashktorab H, Wang TT, Salto-Tellez M, Yeoh KG, et al: Cathepsin $\mathrm{S}$ mediates gastric cancer cell migration and invasion via a putative network of metastasis-associated proteins. J Proteome Res 9: 4767-4778, 2010.

11. Haraguchi N, Inoue $H$, Tanaka F, Mimori K, Utsunomiya $T$, Sasaki A and Mori M: Cancer stem cells in human gastrointestinal cancers. Hum Cell 19: 24-29, 2006

12. Lou Y, Li R, Xiong L, Gu A, Shi C, Chu T, Zhang X, Gu P, Zhong $\mathrm{H}$, Wen $\mathrm{S}$, et al: NAD $(\mathrm{P}) \mathrm{H}$ : quinone oxidoreductase 1 (NQO1) C609T polymorphism and lung cancer risk: a meta-analysis. Tumour Biol 34: 3967-3979, 2013

13. Mikami K, Tabata C, Tabata R, Nogi Y, Terada T, Honda M, Kamiya H, Nishizaki T and Nakano T: Clinical significance of serum angiopoietin-1 in malignant peritoneal mesothelioma. Cancer Invest 31: 511-515, 2013.

14. Rhodes SL, Buchanan DD, Ahmed I, Taylor KD, Loriot MA, Sinsheimer JS, Bronstein JM, Elbaz A, Mellick GD, Rotter JI, et al: Pooled analysis of iron-related genes in Parkinson's disease: Association with transferrin. Neurobiol Dis 62: 172-178, 2014.

15. Pavlou MP and Diamandis EP: The cancer cell secretome: A good source for discovering biomarkers? J Proteomics 73: 1896-1906, 2010.

16. Soltermann A, Ossola R, Kilgus-Hawelski S, von Eckardstein A, Suter T, Aebersold R and Moch H: N-glycoprotein profiling of lung adenocarcinoma pleural effusions by shotgun proteomics. Cancer 114: 124-133, 2008

17. Wang CL, Wang CI, Liao PC, Chen CD, Liang Y, Chuang WY, Tsai YH, Chen HC, Chang YS, Yu JS, et al: Discovery of retinoblastoma-associated binding protein 46 as a novel prognostic marker for distant metastasis in nonsmall cell lung cancer by combined analysis of cancer cell secretome and pleural effusion proteome. J Proteome Res 8: 4428-4440, 2009.

18. Pilch B and Mann M: Large-scale and high-confidence proteomic analysis of human seminal plasma. Genome Biol 7: R40, 2006.

19. Hsu CW, Yu JS, Peng PH, Liu SC, Chang YS, Chang KP and Wu CC: Secretome profiling of primary cells reveals that THBS2 is a salivary biomarker of oral cavity squamous cell carcinoma. J Proteome Res 13: 4796-4807, 2014.

20. Gloghini A, Volpi CC, Caccia D, Gualeni AV, Cilia AM, Carbone A and Bongarzone I: Primary effusion lymphoma: Secretome analysis reveals novel candidate biomarkers with potential pathogenetic significance. Am J Pathol 184: 618-630, 2014.

21. Mathews ST, Chellam N, Srinivas PR, Cintron VJ, Leon MA, Goustin AS and Grunberger G: $\alpha 2-H S G$, a specific inhibitor of insulin receptor autophosphorylation, interacts with the insulin receptor. Mol Cell Endocrinol 164: 87-98, 2000.

22. Pal D, Dasgupta S, Kundu R, Maitra S, Das G, Mukhopadhyay S, Ray S, Majumdar SS and Bhattacharya S: Fetuin-A acts as an endogenous ligand of TLR4 to promote lipid-induced insulin resistance. Nat Med 18: 1279-1285, 2012.
23. Zhao ZW, Lin CG, Wu LZ, Luo YK, Fan L, Dong XF and Zheng H: Serum fetuin-A levels are associated with the presence and severity of coronary artery disease in patients with type 2 diabetes. Biomarkers 18: 160-164, 2013.

24. Kaushik SV, Plaisance EP, Kim T, Huang EY, Mahurin AJ, Grandjean PW and Mathews ST: Extended-release niacin decreases serum fetuin-A concentrations in individuals with metabolic syndrome. Diabetes Metab Res Rev 25: 427-434, 2009.

25. Xu Y,Xu M, Bi Y, Song A, Huang Y,Liu Y,Wu Y, Chen Y, Wang W, $\mathrm{Li}$ X, et al: Serum fetuin-A is correlated with metabolic syndrome in middle-aged and elderly Chinese. Atherosclerosis 216: 180-186, 2011

26. Haukeland JW, Dahl TB, Yndestad A, Gladhaug IP, Løberg EM, Haaland T, Konopski Z, Wium C, Aasheim ET, Johansen OE, et al: Fetuin A in nonalcoholic fatty liver disease: In vivo and in vitro studies. Eur J Endocrinol 166: 503-510, 2012.

27. Yilmaz Y, Yonal O, Kurt R, Ari F, Oral AY, Celikel CA, Korkmaz S, Ulukaya E, Ozdogan O, Imeryuz N, et al: Serum fetuin A/ $\alpha 2$ HS-glycoprotein levels in patients with non-alcoholic fatty liver disease: Relation with liver fibrosis. Ann Clin Biochem 47: 549-553, 2010.

28. Guillory B, Sakwe AM, Saria M, Thompson P, Adhiambo C, Koumangoye R, Ballard B, Binhazim A, Cone C, JahanenDechent W, et al: Lack of fetuin-A ( $\alpha 2-H S-$ glycoprotein) reduces mammary tumor incidence and prolongs tumor latency via the transforming growth factor- $\beta$ signaling pathway in a mouse model of breast cancer. Am J Pathol 177: 2635-2644, 2010.

29. Swallow CJ, Partridge EA, Macmillan JC, Tajirian T, DiGuglielmo GM, Hay K, Szweras M, Jahnen-Dechent W, Wrana JL, Redston M, et al: $\alpha 2 \mathrm{HS}$-glycoprotein, an antagonist of transforming growth factor $\beta$ in vivo. Inhibits intestinal tumor progression. Cancer Res 64: 6402-6409, 2004.

30. Thompson PD, Sakwe A, Koumangoye R, Yarbrough WG, Ochieng J and Marshall DR: $\alpha-2$ heremans schmid glycoprotein (AHSG) modulates signaling pathways in head and neck squamous cell carcinoma cell line SQ20B. Exp Cell Res 321: 123-132, 2014.

31. Bach F, Uddin FJ and Burke D: Angiopoietins in malignancy. Eur J Surg Oncol 33: 7-15, 2007.

32. Fagiani $\mathrm{E}$ and Christofori G: Angiopoietins in angiogenesis. Cancer Lett 328: 18-26, 2013

33. Martin V, Xu J, Pabbisetty SK, Alonso MM, Liu D, Lee OH, Gumin J, Bhat KP, Colman H, Lang FF, et al: Tie2-mediated multidrug resistance in malignant gliomas is associated with upregulation of ABC transporters. Oncogene 28: 2358-2363, 2009.

34. Mazzieri R, Pucci F, Moi D, Zonari E, Ranghetti A, Berti A, Politi LS, Gentner B, Brown JL, Naldini L, et al: Targeting the ANG2/TIE2 axis inhibits tumor growth and metastasis by impairing angiogenesis and disabling rebounds of proangiogenic myeloid cells. Cancer Cell 19: 512-526, 2011.

35. Tait CR and Jones PF: Angiopoietins in tumours: The angiogenic switch. J Pathol 204: 1-10, 2004.

36. Tong Z, Kunnumakkara AB, Wang H, Matsuo Y, Diagaradjane P, Harikumar KB, Ramachandran V, Sung B, Chakraborty A, Bresalier RS, et al: Neutrophil gelatinase-associated lipocalin: A novel suppressor of invasion and angiogenesis in pancreatic cancer. Cancer Res 68: 6100-6108, 2008.

37. Yang J, McNeish B, Butterfield C and Moses MA: Lipocalin 2 is a novel regulator of angiogenesis in human breast cancer. FASEB J 27: 45-50, 2013

38. Iannetti A, Pacifico F, Acquaviva R, Lavorgna A, Crescenzi E, Vascotto C, Tell G, Salzano AM, Scaloni A, Vuttariello E, et al: The neutrophil gelatinase-associated lipocalin (NGAL), a $\mathrm{NF}-\kappa \mathrm{B}$-regulated gene, is a survival factor for thyroid neoplastic cells. Proc Natl Acad Sci USA 105: 14058-14063, 2008.

39. Suk K: Proteomic analysis of glioma chemoresistance. Curr Neuropharmacol 10: 72-79, 2012.

40. Zheng LT, Lee S, Yin GN, Mori K and Suk K: Down-regulation of lipocalin 2 contributes to chemoresistance in glioblastoma cells. J Neurochem 111: 1238-1251, 2009.

41. Squarize CH, Castilho RM, Abrahao AC, Molinolo A, Lingen MW and Gutkind JS: PTEN deficiency contributes to the development and progression of head and neck cancer. Neoplasia 15: 461-471, 2013. 